\title{
Crowned eagles rarely prey on livestock in central Argentina: persecution is not justified
}

\author{
José Hernán Sarasola ${ }^{1,3, *}$, Miguel Ángel Santillán' ${ }^{1}$ Maximiliano Adrián Galmes ${ }^{1,2}$ \\ ${ }^{1}$ Centro para el Estudio y Conservación de las Aves Rapaces en Argentina (CECARA), \\ Universidad Nacional de La Pampa-CONICET, Avda. Uruguay 151, 6300 Santa Rosa, La Pampa, Argentina \\ ${ }^{2}$ The Peregrine Fund, 5668 West Flying Hawk Lane, Boise, Idaho 83709, USA \\ ${ }^{3}$ Present address: Estación Biológica de Doñana - CSIC, Avda. Américo Vespucio s/n, 41092 Sevilla, Spain
}

\begin{abstract}
Raptors have been reported to prey on livestock, causing considerable conflicts between birds of prey and local human communities. Previous studies have documented that human persecution is the most important threat to the endangered crowned eagle Harpyhaliaetus coronatus in central Argentina, due to a local belief that crowned eagles heavily and consistently prey on livestock. However, there are no empirical data supporting this assertion. Such information is crucial to evaluating possible measures to mitigate this human-wildlife conflict. We evaluated the feeding ecology of crowned eagles in semiarid habitats of central Argentina during the breeding seasons of 2002 to 2009. We also evaluated whether eagles are responsible for livestock predation and examined spatial-temporal variation in crowned eagles' food habits. We identified 598 prey items consisting almost entirely of native prey: mammals $(67.7 \%)$, reptiles $(16.2 \%)$, birds $(3.3 \%)$, fish $(2.5 \%)$, and invertebrates $(16.9 \%)$. We only recorded $1(0.17 \%)$ occurrence of livestock prey remains, belonging to a domestic goat Capra hircus. Occurrences of the 4 main prey groups were not affected by habitat type or season. However, reptiles were recorded in higher numbers at sites where the diet of eagles was addressed by direct observation and video recording. Contrary to other human-predator conflicts worldwide, and assuming that the single livestock prey was not scavenged, our results show that crowned eagles rarely prey on livestock. We advocate reducing human-wildlife conflicts by implementing management and conservation measures and by educating local communities with respect to the ecological role of crowned eagles and other predators.
\end{abstract}

KEY WORDS: Crowned eagle - Harpyhaliaetus coronatus - Conservation ' Persecution · Human-wildlife conflict · Feeding ecology $\cdot$ Central Argentina

\section{INTRODUCTION}

Large predators are among the most difficult species to preserve: they occur at extremely low densities, are distributed across large areas, and may come into conflict with human populations in parts of their geographic ranges. These conflicts mainly consist of predation on livestock (Thirgood et al. 2005), which can result in the predator being persecuted, trapped, or killed, with corresponding negative effects on its conservation (Etheridge et al. 1997). Human persecution has been identified as a serious threat to many birds of prey. For example, it is the main cause for the population decline of golden eagles Aquila chrysaetus in Europe (Whitfield et al. 2004) and the principal factor limiting population growth of hen harriers Circus cyaneus in the UK (Thirgood et al. 2000). Dealing with these conflicts requires data on the ecological circumstances associated with livestock predation, as well as on the relative economic impacts of such conflicts. These data are crucial for the establishment of conservation plans and management decisions that aim to mitigate or avoid conflicts between wildlife and local human communities. 
The crowned eagle Harpyhaliaetus coronatus is one of the largest birds of prey in South America, ranging from southern Brazil to northern Patagonia in Argentina (Fergusson-Lees \& Christie 2001). It mainly inhabits open woodlands in xerophytic forest typical of several biomes in Brazil, Paraguay, and Argentina. The crowned eagle has been included in the threatened fauna lists of Argentina as an endangered species (López-Lanús et al. 2008, Chebez et al. 2008) and is currently considered extinct in Uruguay, where it has not been reported since 1930 (Alvarez 1933). The International Union for the Conservation of Nature (IUCN) listed it as a Vulnerable species until 2004, when it was placed in the Endangered category. The world population is estimated at less than 1000 individuals, and populations are declining (BirdLife International 2008). Despite its wide range, critical conservation status, and ongoing population decreases, few studies exist on wild populations of this species, and many aspects of its biology are still unknown, including habitat use, habitat selection, and feeding ecology. Although suspected threats to crowned eagles include habitat loss (Bellocq et al. 1998) and other human-related mortality (i.e. electrocution on power lines), only human persecution has been adequately documented. A recent study by Sarasola \& Maceda (2006), based on interviews with local landowners and rural workers, indicated that (1) human persecution is the most important cause of mortality of crowned eagles in Central Argentina; (2) the number of eagles found killed, injured, or trapped was relatively high $(\mathrm{n}=20)$; and (3) local people cited eagle predation on livestock as the justification for persecution. Unfortunately, the food habits of crowned eagles have been only poorly and anecdotally documented (Maceda et al. 2003, Maceda 2007, Chebez et al. 2008), so little evidence exists to verify whether this local belief is grounded in the reality of current predatory habits of these birds. We thus examined the feeding ecology of crowned eagles in an area of central Argentina where human persecution was previously documented. We evaluated whether eagles are responsible for livestock predation and whether livestock constitutes a high percentage of prey items in the diet of crowned eagles, or is at least similar to those reported for other documented raptor-human conflicts. In addition, we examined spatial and temporal variation in the diet of crowned eagles by evaluating the occurrence of main prey items in different habitats and seasons.

\section{MATERIALS AND METHODS}

Study area. Our study was conducted in an area of ca. $10000 \mathrm{~km}^{2}$ in central and western parts of La Pampa province, Argentina (Fig. 1). The natural landscape in this region includes 2 of the most exten- sive habitat types in Argentina, the Espinal and the Monte Desert biomes (Cabrera 1976), which are also 2 of the representative habitat types for crowned eagles in southern South America. The Espinal ecoregion is located in central Argentina, extending from central Santa Fe through the province of Córdoba and San Luis to the south of La Pampa province. Vegetation types include deciduous xerophytic forests, palm groves, grassy savannahs, grassy steppes, and bushy steppes. Climax communities are dominated by trees of the genus Prosopis, represented by the caldén $P$. caldenia in La Pampa province. The Monte Desert is located in northcentral Argentina and extends along the eastern foothills of the Andes until it reaches the Patagonian steppe. This ecoregion is dominated by occasional open scrublands formed by resinous evergreen bushes. In both ecoregions, the climate is temperatearid with very little rainfall (between 80 and $250 \mathrm{~mm}$ and between 350 and $450 \mathrm{~mm} \mathrm{yr}^{-1}$ for the Monte Desert and Espinal biomes, respectively; Fernandez \& Busso 1997).

Methods. Between 2002 and 2009, we collected information on the food habits of crowned eagles at 15 breeding territories from an area where human persecution has previously been reported (Fig. 1). Sampling was conducted during 1 of the 2 local lambing seasons in this area (spring-summer), when lambs are suspected to be more susceptible to predation. Pellets and prey remains were collected at 11 nests and at perch sites used by adults near the nests. Pellets were hydrated and broken apart by hand, and prey remains were identified using reference collections at CECARA (Universidad Nacional de La Pampa, Argentina) and identification keys (Cei 1986, Pearson 1995) to the lowest possible taxonomic level. In addition, we determined eagle diets at 4 nest sites from mid-December to mid-February by recording prey items that adult eagles delivered to the nestlings. First, 2 nests located near the Jagüel del Monte area were monitored, one in 2004 and the other in 2005, with a time-lapse video recorder (VCR Panasonic AG-1070 DC). The camera was housed in a waterproof compartment and placed approximately $1 \mathrm{~m}$ above the nest. Power and video lines from the camera were connected to a time-lapse VCR located on the ground about $100 \mathrm{~m}$ from the nest. Power was supplied to the video unit by one $12 \mathrm{~V}$ battery connected to a solar panel. The VCR was housed in a waterproof compartment and was programmed to record during two $8 \mathrm{~h}$ time blocks (from 06:00 to $14: 00 \mathrm{~h}$ and from 14:00 to 22:00 h). Because little is known about the timing of hunting by crowned eagles, these time blocks were selected randomly. In 2004, the camera was placed at the nest when the 


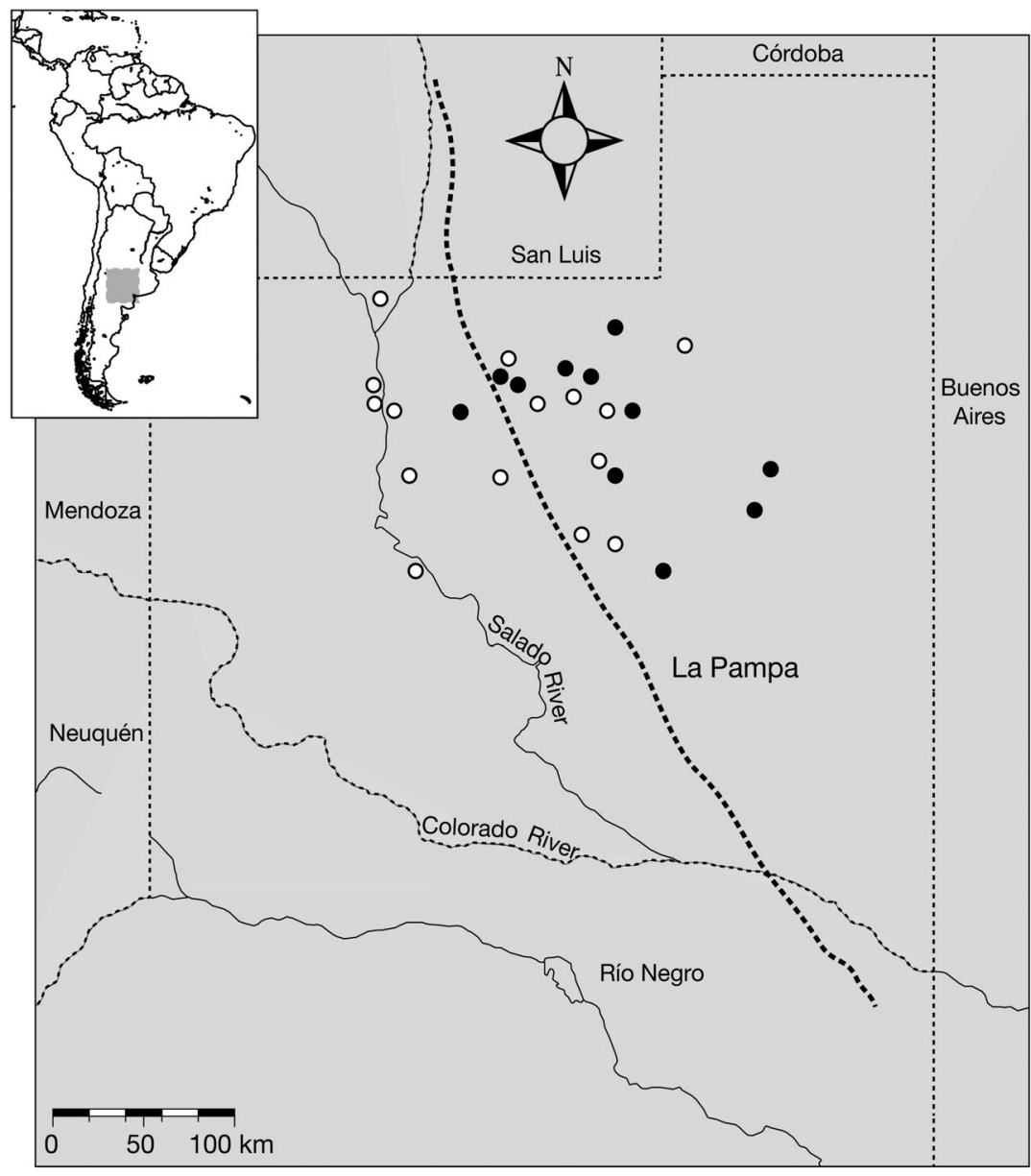

Fig. 1. Study area $\left(37^{\circ} 02^{\prime} \mathrm{S}, 65^{\circ} 34^{\prime} \mathrm{W}\right)$ in La Pampa province, central Argentina, showing locations of crowned eagle breeding territories where diet information was obtained $(O)$ and incidents of human persecution reported by Sarasola \& Maceda (2006) ( ). The thick dashed line represents the boundary between the Monte Desert (west) and Espinal (east) biomes

We evaluated spatial and temporal variation of prey consumed by crowned eagles in western La Pampa. For each prey group, we built generalized linear models (GLMs; McCullagh \& Nelder 1989) where the response variable was the number of individuals consumed in each of 4 prey categories (mammals, birds, reptiles, and fish), and the independent variables were habitat (2-level factor: forest or scrubland) and year. We considered each breeding territory as a sample and incorporated the independent variables related to the breeding sites (habitat type and year when sampling was conducted). Habitat features are important since they may determine local presence and availability of different prey types; by including year as the independent variable, we attempted to account for temporal variability in consumption of each prey group. We also included a third variable related to the methodology employed to survey the food habits at each site (i.e. pellets and prey remains, direct observations, and video recording), since using different methods to study raptor diet can lead to biased representation of certain prey types (Margalida et al. 2007). By including this variable in the analysis, we evaluated possible differences among breeding sites linked to methodology-dependent biases in prey identification at a coarse taxonomic level

young eagle was about 1 wk old; in 2005, the camera was placed when the egg was still unhatched. In the 2007 and 2008 breeding seasons, dawn-to-dusk direct observations were conducted at 2 nests, one in each year. Observations were conducted between 06:00 and 22:00 h using a 20-60× spotting scope (Bushnell) and 2 observers located $300 \mathrm{~m}$ from the nest to minimize disturbance.

We calculated total prey biomass in the diet by multiplying the mean mass of each prey type by the number of that prey recorded in the diet of crowned eagles. To compute prey biomass, we obtained the mean body mass of small mammal species and arthropods from Sarasola et al. (2003, 2007). J. Maceda (unpubl. data) provided data for the body mass of snakes, armadillos, birds, and lagomorphs, while body mass of carnivores was obtained from Redford \& Eisenberg (1992). Unidentified prey items were not considered for prey biomass calculation. (i.e. order). For modeling purposes, we considered only those sites sampled where the total number of identified prey was $>15$ ( $\mathrm{N}=13$ breeding sites $)$. All models were built using a Poisson error distribution and a log link function.

The significance of habitat, method, and year as explanatory variables of consumption of each prey category was tested using information theory. We built 8 models (all possible variable combinations of main effects without interactions) for each prey category species and used the Akaike Information Criterion (AIC, Burnham \& Anderson 2002), which takes into account both the information explained by the model and its complexity in terms of number of estimated parameters, generating a rank from the best to the least likely model. Within a prey category, each model was considered as a hypothesis explaining the consumption of that prey. For this set of models, we first calculated the second-order AIC (AICc), which is simi- 
lar to AIC but corrected for small sample size, the $\triangle \mathrm{AICC}$ (the differences in AICc with respect to the AICc of the best candidate model), and AICc weight $(w)$. The best hypothesis was weighed against the others using AICc weight, which gives an estimation of the likelihood of the hypothesis given the data. Correlations between independent variables were tested, showing non-significant correlations ( $p>0.20)$. Statistical analyses were performed using S-PLUS 2000 software (MathSoft 1999).

\section{RESULTS}

In total, 513 prey items were identified from 67 pellets and 221 prey remains collected during the study. Dawn-to-dusk observations at nests totaled $280 \mathrm{~h}$, and video observations totaled $400 \mathrm{~h}$. In total, 85 prey delivered to young eagles by their parents were recorded during direct observations and video recording sessions at nests. Medium-sized and small mammals accounted for the majority of prey items recorded (edentates: $48.6 \%$, rodents and small marsupials: $13.7 \%$, small carnivores and lagomorphs: $5.2 \%$, , followed by invertebrates $(16.9 \%)$, reptiles $(16.2 \%)$, birds $(3.3 \%)$, and fish $(2.6 \%$; Table 1$)$. Reptiles were mainly represented by snakes, including venomous species such as the crossed pit viper Bothrops alternatus and the Patagonian pit viper $B$. ammodytoides. The diet of crowned eagles was independent of livestock farming. We recorded livestock as a prey item $(0.2 \%)$ at only 1 nest: a humerus of a domestic goat Capra hircus. Livestock prey were not recorded at any of the nests monitored by direct observations or video recording.

The consumption of mammals, fish, and birds did not vary spatially or temporally, as it was independent of year/season and habitat type. However, fish were recorded in crowned eagles' diet only at those nest sites located close to the Salado River (Fig. 1), a habitat feature that was not considered in our coarse, 2-level habitat categorization. The best models for these prey groups included only a constant (Table 2), indicating that the occurrence of these prey was also independent of the methodological approach employed in the assessment of the diet of crowned eagles. The occurrence of reptiles in the diet was also independent of habitat type and year but not for the method employed in the analysis of diet. Reptiles were recorded in higher numbers at sites where the method employed was direct observation or video recording (mean $\pm \mathrm{SE}=19.2 \pm 5.6$ reptiles, $\mathrm{N}=4$ sites) than in those where the diet was examined by the analysis of pellets and prey remains (mean $\pm \mathrm{SE}=$ $4.6 \pm 2.2$ reptiles, $\mathrm{N}=9$ sites).

\section{DISCUSSION}

Contrary to local beliefs, our results show that crowned eagles in semiarid habitats of central Argentina do not prey on livestock on a regular basis. In the southern Espinal and Monte desert biomes, crowned eagles preyed almost exclusively on native wild species, mainly armadillos and other small to medium-sized mammals and snakes. Nestling eagles were also fed natural prey items, despite the availability of domestic lambs. The relative abundance of snakes in the diet was in agreement with Amadon's (1982) predictions regarding the feeding behavior of crowned eagles based on morphology (e.g. rough, reticulate tarsi that protect against venomous snake bites).

Only 1 domestic goat was recorded as a prey item (less than $0.2 \%$ of the total items recorded), indicating the occasional nature of such feeding behavior. This single report came from a nest in western La Pampa, where the number of eagles killed is lower than reported for the Espinal (Fig. 1).This rate of predation on livestock, assuming that this single goat was not scavenged as carrion, a feeding behavior previously documented for crowned eagles (Maceda et al. 2003), is considerably lower than those observed in other well-documented conflicts between raptors and humans worldwide. For example, domestic lamb remains represented $1.1 \%$ to $8 \%$ of the prey items in the diet of black eagles Aquila verreauxii in South Africa (Davies 1999), and a survey on lamb carcasses at 2 ranches in Montana (USA) determined that golden eagles were responsible for an average of $24 \%$ of sheep losses between 1974 and 1985 (Matchett \& O'Gara 1987). Similarly, it was calculated that hen harriers could remove up to $24 \%$ of red grouse chicks on grouse moors in the UK (Redpath 1991).

Our results support the argument that persecution of crowned eagles stems from a social and cultural attitude towards large predators in general, irrespective of whether predation by raptors or carnivores causes any economic losses (Sarasola \& Maceda 2006). In addition, crowned eagles appear to be flexible dietary generalists that are not dependent on livestock farming. The proportion of some prey items, particularly fish and reptiles, varied by region. Reptiles were more frequently recorded at breeding sites located in Loventué county, and fish were recorded only at nest sites close to the Salado River (Fig. 1). The occurrence of fish in the diet was linked to periods in which the river level dropped as a result of river flow regulation upstream in Mendoza province (Fig. 1), and fish either died or were confined to small ponds. Crowned eagles might be expected to modify their diet in similar ways when faced with environmental changes in land use and 
Table 1. Prey consumed by crowned eagles, determined by analysis of pellets and prey remains, direct observations, and video recording at 15 breeding territories from 2002 to 2009. Results are expressed as absolute frequency for each of the methodologies employed and as total percentage in number $(\% \mathrm{~N})$ and in mass $(\% \mathrm{M})$. Totals are given in bold; $(-): 0$

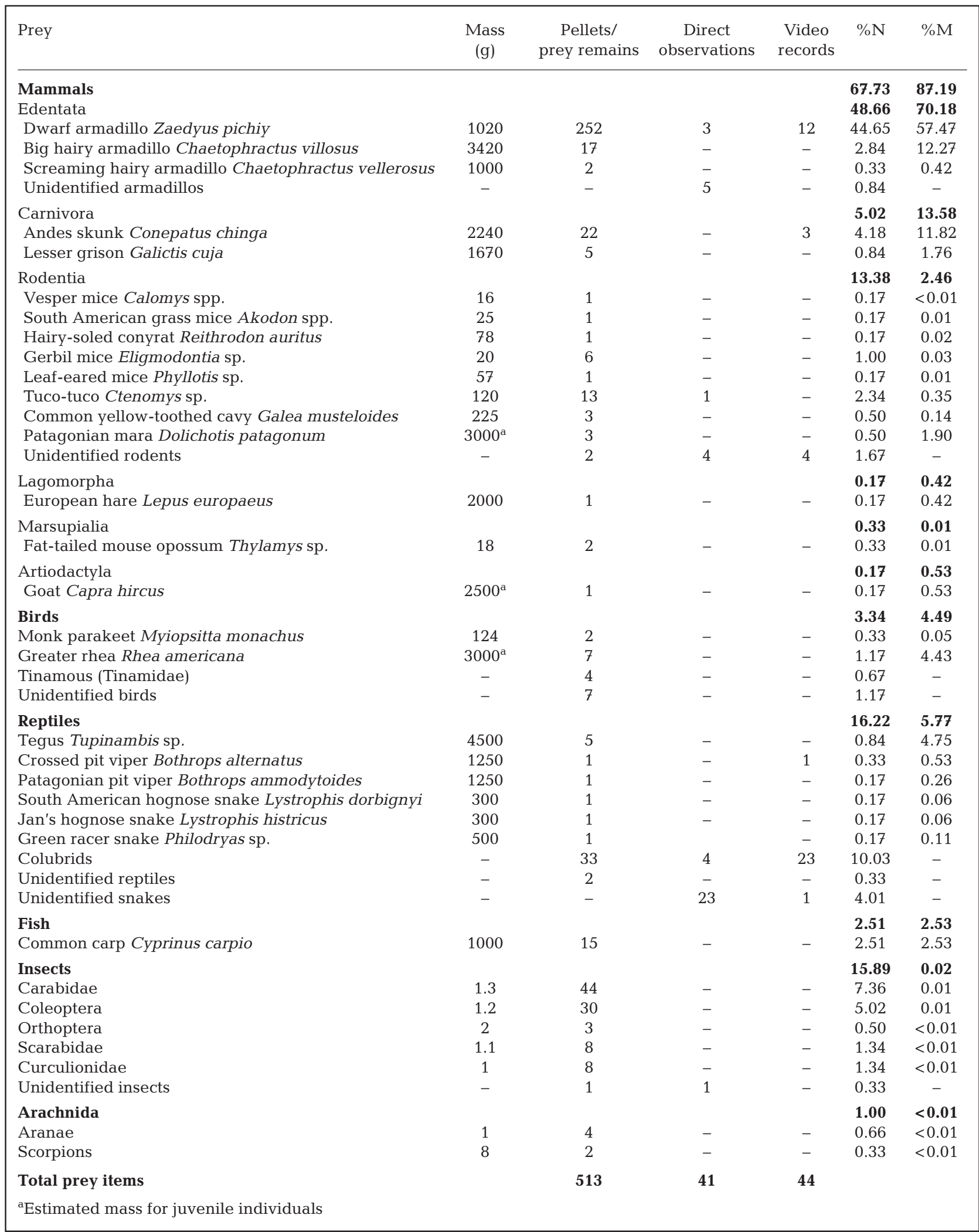


Table 2. Best models explaining the consumption of the 4 vertebrate prey groups by crowned eagles in western La Pampa, Argentina. The intercept and coefficient for the variables included in the top-ranking models $(\triangle \mathrm{AICc}<4)$ for each prey group are given with SE in parentheses. For each model, the corrected Akaike's Information Criterion (AICc), the difference in AICc between are given; where no model name is given, the best model was a null model

\begin{tabular}{|lcccccc|}
\hline Prey group & \multirow{2}{*}{ Model } & Intercept & Coefficient & AICc & $\Delta$ AICc & $w$ \\
\hline Mammals & & $3.18(0.05)$ & & 78.53 & 0.00 & 0.93 \\
Birds & & $0.51(0.22)$ & & 50.11 & 0.00 & 0.89 \\
Reptiles & METHOD & $2.45(0.10)$ & $-0.53(0.12)$ & 62.83 & 0.00 & 0.72 \\
Fish & & & $0.38(0.07)$ & & & \\
& & $0.22(0.25)$ & & 55.15 & 0.00 & 1.00 \\
\hline
\end{tabular}
the current model and the best model $(\triangle \mathrm{AICC})$, and the Akaike weights $(w)$

surprising under changes in livestock densities. Thus, the current attitude toward crowned eagles could be the result of eagles' predatory behavior in the past and historic perceptions of its economic impact.

Illegal killing of crowned eagles is also suspected to occur in some areas of Paraguay (BirdLife International 2008) and was probably the main cause of local extinction in Uruguay where the last record for a crowned eagle came from a shot individual (Alvarez 1933). However, no quantitative data exist on direct persecution in agricultural practices. The sheep industry, which played a major role in European settlement after the eradication of indigenous people in this region, peaked around 1960 (3.5 million sheep for La Pampa province; DNDEC 1960) but decreased steadily thereafter. The reduction in quantity and quality of forage as well as the use of synthetic materials and other economic factors were blamed for this decline (Soriano 1983). From 1988 to 2002, for example, the number of sheep in La Pampa province declined from 472000 to 205000 head; cattle numbers increased slightly over the same period of time (INDEC 1988, 2002; Fig. 2). By contrast, goats compose only a small fraction of total livestock raised in this province (35000 in 2002). Currently, sheep are mainly raised for subsistence farming by local people rather than commercially, and both sheep and goats are raised in small herds and at low densities. Livestock losses due to predation may be greater when herds are larger (Dar et al. 2009), and a shift in the feeding behavior of crowned eagles would not be

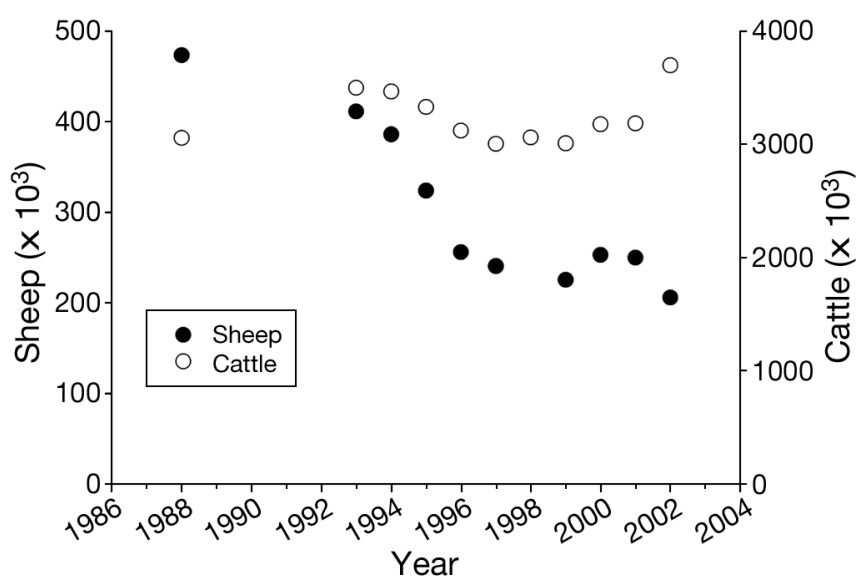

Fig. 2. Yearly variation in the total number of cattle and sheep in La Pampa province, Argentina, between 1988 and 2002. No data are available for sheep in 1998. Data from 1991 to 2000 are from Encuesta Nacional Agropecuaria (www.indec. mecon.ar) and for 1988 and 2002 from Censo Nacional Agropecuario (INDEC 1988, 2002) those countries or in other parts of the species' range. Given the data presented in this study, further studies to evaluate the extent of crowned eagle predation on livestock should be conducted in areas where human persecution is suspected or documented.

The central and western parts of La Pampa province have been identified as high-priority areas for field research and conservation for crowned eagles, due to the high number of field records and to the absence of other protected areas and reserves (Bellocq et al. 2002). All of the current known nesting areas of crowned eagles are managed by private owners, and any conservation measure will depend strongly on including the local community in management decisions and conservation action. Additional management and conservation measures would also include monitoring and reinforcement of legal regulations. In addition, and because crowned eagle predation on livestock is almost nonexistent, economic compensation to farmers at high rates (e.g. more than $100 \%$ of the value of livestock) could be implemented in those cases in which livestock losses due to crowned eagle predation are well documented.

This study shows that there is a lack of systematic livestock predation by crowned eagles in central Argentina and suggests that persecution of these birds can be reduced without negatively affecting local agricultural practices. The establishment of educational campaigns to disseminate accurate information on eagle diet, rather than costly and difficult actions to mitigate human-wildlife conflicts, are the most urgent and highly prioritized conservation measures that should be taken to preserve crowned eagle populations in this broad region.

Acknowledgements. We thank C. Solaro, M. Reyes, M. De Benito, L. Pahl, M. Peters, C. Staveley, J. Carslile, M. del Mar Contaldi, and J.J. Maceda for help with field research, and V. Salvador for help with data analysis. We thank many local landowners from La Pampa province who gave us permission 
to access their ranches and provided information on the location of crowned eagle nests and perch sites. We thank L. Sympson and the University of California at Berkeley for providing the video recording equipment and $\mathrm{H}$. Vargas for providing helpful comments on an early version of this manuscript. We appreciate the improvements in English usage made by C. Riehl through the Association of Field Ornithologists' program of editorial assistance. We also appreciate the suggestions and comments made by M. Reed, R. Brook, and an anonymous reviewer that greatly improved the manuscript. This study received financial support from the Peregrine Fund (USA), the Universidad Nacional de La Pampa (Argentina), IDEA WILD (USA) and the Dirección de Recursos Naturales of La Pampa province (Argentina). J.H.S. was founded by the Spanish Ministry of Education and Science through the postdoctoral programme 'Juan de la Cierva.' M.A.G. was supported by The Peregrine Fund.

\section{LITERATURE CITED}

Alvarez T (1933) Observaciones biológicas sobre las aves del Uruguay. An Mus Hist Nat Montev 2:1-50

Amadon D (1982) A revision of the sub-buteonine hawks. Am Mus Novit 2741:1-20

Bellocq MI, Bonaventura SM, Marcelino FN, Sabatini M (1998) Habitat use of crowned eagles (Harpyhaliaetus coronatus) in the southern limits of the species' range. J Raptor Res 32:312-314

Bellocq MI, Ramírez-Llorens P, Filloy J (2002) Recent records of crowned eagles (Harpyhaliaetus coronatus) from Argentina, 1981-2000. J Raptor Res 36:206-212

BirdLife International (2008) Harpyhaliaetus coronatus. In: IUCN Red List of threatened species. Version 2009.1. www.iucnredlist.org.

Burnham KP, Anderson DR (2002) Model selection and multimodel inference: a practical information-theoretic approach. Springer-Verlag, New York, NY

Cabrera AL (1976) Regiones fitogeográficas Argentinas. In: Ferreira Sobral EF (ed) Enciclopedia Argentina de agricultura y jardinería. Editorial ACME, Buenos Aires, p 1-85

Cei JM (1986) Reptiles del centro, centro-oeste y sur de la Argentina. Herpetofauna de zonas áridas y semiáridas. Monografie IV. Museo Regionale di Scienze Naturali, Torino, p 112-120

Chebez JC, Maceda JJ, Pereyra-Lobos R (2008) Águila coronada. In: Chebez JC (ed) Los que se van. Fauna Argentina amenazada. Editorial Albatros, Buenos Aires, p 177-186

Dar NI, Minhas RA, Zaman Q, Linkie M (2009) Predicting the patterns, perceptions and causes of human-carnivore conflict in and around Machiara National Park, Pakistan. Biol Conserv 142:2076-2082

Davies RAG (1999) The extent, cost and control of livestock predation by eagles with a case study on black eagles (Aquila verreauxii) in the Karoo. J Raptor Res 33:67-72

DNDEC (Dirección Nacional de Estadísticas y Censos) (1960) Censo nacional agropecuario 1960. DNDEC, Buenos Aires

Etheridge B, Summers RW, Green RE (1997) The effects of illegal killing and destruction of nests by humans on the population dynamics of the hen harrier Circus cyaneus in Scotland. J Appl Ecol 34:1081-1105

Fergusson-Lees J, Christie DA (2001) Raptors of the world. Helm Identification Guides, London
Fernandez OA, Busso CA (1997) Arid and semi-arid rangelands: two thirds of Argentina. Rala Rep 200:41-60

INDEC (Instituto Nacional de Estadísticas y Censos) (1988) Censo nacional agropecuario 1988. Resultados generales provincia de La Pampa. INDEC, Secretaría de Planificación, Buenos Aires

INDEC (2002) Censo nacional agropecuario 2002. Resultados generales provincia de La Pampa. www.indec.mecon.ar

López-Lanús B, Grilli P, Di Giacomo AS, Coconier E, Banchs R (2008) Categorización de las aves de la Argentina según su estado de conservación. Aves Argentinas/AOP y Secretaría de Ambiente y Desarrollo Sustentable, Buenos Aires

Maceda JJ (2007) Biología y conservación del águila coronada (Harpyhaliaetus coronatus) en Argentina. Hornero 22: $159-171$

Maceda JJ, Sarasola JH, Pessino MEM (2003) Presas consumidas por el águila coronada (Harpyhaliaetus coronatus) en la provincia de La Pampa. Ornitol Neotrop 14:419-422

Margalida A, Mañosa S, Bertran J, García D (2007) Biases in studying the diet of the bearded vulture. J Wildl Manag 71:1621-1625

Matchett MR, O'Gara BW (1987) Methods of controlling golden eagle depredation on domestic sheep in southwestern Montana. J Raptor Res 21:85-94

MathSoft (1999) S-Plus 2000 guide to statistics. Data Analysis Products Division, Seattle, WA

McCullagh P, Nelder JA (1989) Generalized linear models, 2nd edn. Chapman \& Hall, London

Pearson O (1995) Annotated keys for identifying small mammals living in or near Nahuel Huapi National Park or Lanín National Park, southern Argentina. Mastozool Neotrop 2:99-148

Redford KH, Eisenberg JF (1992) Mammals of the Neotropics. The southern cone, Vol 2. University of Chicago Press, Chicago, IL

> Redpath S (1991) The impacts of hen harriers on red grouse breeding success. J Appl Ecol 28:659-671

> Sarasola JH, Maceda JJ (2006) Past and current evidence of persecution of the endangered crowned eagle Harpyhaliaetus coronatus in Argentina. Oryx 40:347-350

Sarasola JH, Santillan MA, Galmes MA (2003) Food habits and foraging ecology of American kestrels in the semiarid forests of Central Argentina. J Raptor Res 37:236-243

Sarasola JH, Santillan MA, Galmes MA (2007) Comparison of food habits and prey selection of the white-tailed kite (Elanus leucurus) between two land use types in central Argentina. Stud Neotrop Fauna Environ 42:85-91

Soriano A (1983) Deserts and semi-deserts of Patagonia. In: West NE (ed) Ecosystems of the world - temperate deserts and semi-deserts. Elsevier Scientific, Amsterdam, p 423-460

> Thirgood S, Redpath S, Newton I, Hudson P (2000) Raptors and red grouse: conservation conflicts and management solutions. Conserv Biol 14:95-104

Thirgood S, Woodroffe R, Rabinowitz A (2005) The impact of human-wildlife conflicts on human lives and livelihoods. In: Woodroffe S, Thirgood S, Rabinowitz A (eds) People and wildlife: conflict or coexistence? Cambridge University Press, Cambridge, p 13-26

Whitfield DP, Fielding AH, McLeod DRA, Haworth PF (2004) The effects of persecution on age of breeding and territory occupation in golden eagles in Scotland. Biol Conserv 118:249-259 